\title{
Exploring the Simultaneity in Public Assistance and Abortion
}

\author{
Hal W. Snarr \\ Westminster College, Economics, Salt Lake City, USA \\ Email: hsnarr@westminstercollege.edu
}

Received December 27, 2012; revised February 10, 2013; accepted March 10, 2013

Copyright (C) 2013 Hal W. Snarr. This is an open access article distributed under the Creative Commons Attribution License, which permits unrestricted use, distribution, and reproduction in any medium, provided the original work is properly cited.

\begin{abstract}
This paper studies the effects of time limits on abortion and welfare participation of low-income pregnant single females who may or may not have other children. In doing this, I explore the presence and nature (if it exists) of simultaneity in abortion and welfare participation. The results indicate that time limits, childcare and abortion subsidies, and public assistance payments are linked to abortion. In addition, the results indicate time limits simultaneously reduce welfare enrollments and increase abortion among low-income childless single pregnant females, and trigger abortion and shorter stays on welfare of low-income pregnant mothers. Thus, future empirical work should account for simultaneity of abortion and welfare participation.
\end{abstract}

Keywords: Provision and Effects of Welfare Programs; Marriage; Family Structure; Fertility

\section{Introduction}

The Centers for Disease Control and Prevention (CDC) latest Morbidity and Mortality Weekly Report reports a continued decadal long accelerating decline in the abortion rate to 15.1 per 1000 women aged $15-44$ years [1], which is shown in Figure 1. The Report also identifies several factors driving this trend. The abortion rate was 8.5 for whites, 19.3 for Hispanics and 32.5 for blacks. Of the women who obtained abortions in 2009,85 percent were not married, 72 percent were between 20 and 34 years of age, and 40, 46 and 14 percent had zero, one or two, or three or more live births. Sixty-four percent of abortions were obtained between the gestational age of zero and eight weeks, while 1.3 percent were obtained at a gestational age of 21 weeks or more. The lowest abortion rate was in Mississippi, the state with the highest teen birthrate and few abortion providers, while the highest was in New York, the state with the second most abortion providers. Other contributing factors cited by the Report include state laws, the economy, and access to healthcare and contraception.

A limited number of mostly empirical studies identify another contributing factor to the decline in abortion incidence [2-5]. The evidence in these studies indicates a link between public policy and abortion. This is not surprising because the stated goals of the 1996 legislation, which replaced Aid to Families Dependent Children
(AFDC) with Temporary Assistance for Needy Families (TANF), is to "end the dependence of needy parents on government benefits" [6] and "prevent and reduce the incidence of out-of-wedlock pregnancies" [7]. The U.S. Congress incentivized states to achieve these goals by directing the U.S. Department of Health and Human Services to award bonuses to states achieving the largest reductions in out-of-wedlock birth rates with constant or falling abortion rates [8].

U.S. welfare reform also altered the incentive structure

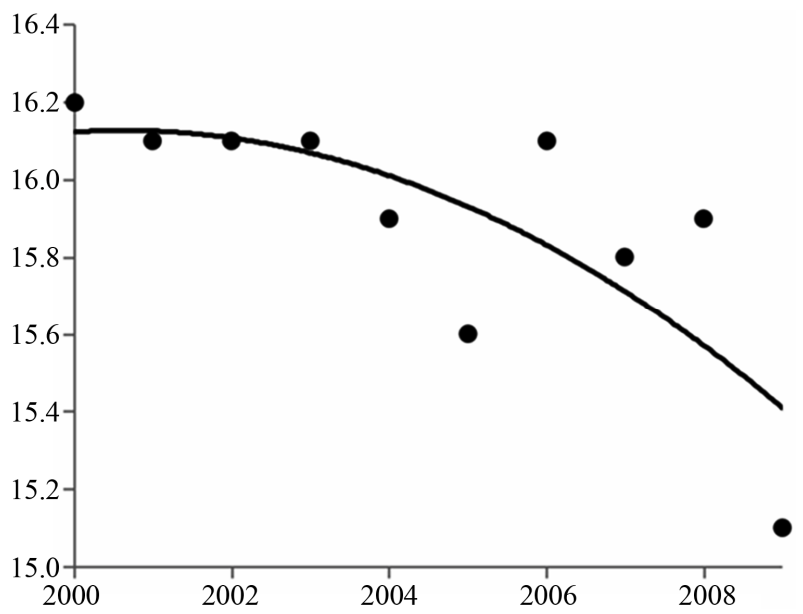

Figure 1. U.S. Abortion rate per 1000 women aged 15 - 44 years. Source: [1]. 
heads of which low-income households are faced with. Under the new program, participants are required to work, are limited to 5 years of assistance, and can lose all or some assistance money if they fail to work. To date, only [5] have theoretically modeled the abortion effects of welfare reform. They examine two specific aspects of welfare reform: permitting childless pregnant single females to enroll in TANF [9] and lump-sum TANF diversion payments [10]. Their model implies that lump-sum diversion TANF payments have lower abortion among low-income mothers but raise it for women who are childless and pregnant. The empirical results only support the first part of that statement.

This paper focuses on the effect of time limits on abortion to explore the simultaneity of abortion and welfare participation, which may explain why [5] rejected their second hypothesis: diversion payments and TANF eligibility for low-income women who are childless and pregnant increase abortion incidence. This issue should concern researchers because failing to account for it can bias coefficient estimates. Although scant research accounts for simultaneity in welfare program participation and out-of-wedlock births [11,12], simultaneity of participation and abortion has been overlooked.

\section{Model of Pregnancy Termination and Welfare Enrollment}

The link between abortion incidence of childless pregnant single females and two TANF provisions is theoretically modeled in [5]. It focused on some states permitting childless pregnant single females to enroll in TANF and using lump-sum payments to divert potential participants from enrolling in TANF. In this section, I use that model to study the effects of time limits on pregnancy termination and welfare program participation decisions of low-income Pregnant Singles (PS) who may or may not have other children.

\subsection{The Budget Constraint}

Several factors affect PS's budget constraint. She must decide between pregnancy termination or an out-of-wedlock birth in month $t=0$. If termination is chosen, $A=1$, otherwise $A=0$. PS may have other children. If so, $O=1$, otherwise $O=0$. Pregnancy termination costs $K$ in month 0 , but birth costs $k$ each month thereafter $(t>0)$ until the child reaches adulthood in period $T$. Following [5], public assistance payment $P$ exceeds PS's subsistence needs but her earnings $(Y)$ do not because her skill level is too low $(P>Y)$.

In the first scenario, PS has other children $(O=1)$ and is enrolled in welfare in month 0 . If PS chooses birth in month zero, $t$ is the age of her newborn. This allows her to receive monthly public assistance payment $P$ until her newborn reaches adulthood at age $T$. If PS chooses termination, her youngest reaches adulthood earlier. For example, if this child is 12 months old at month 0 , she can receive payment $P$ for $T-12$ consecutive months. Given that PS's planning horizon is longer if she chooses birth, I differentiate the two planning horizons with $T_{1}$ and $T_{0}$ where $T_{0}>T_{1}$. More generally, the planning horizon is denoted $T_{A}$ with the subscript taking on the values of indicator $A$. After month $T_{A}$, PS must return to work because her youngest child has become an adult. She earns $Y$ every month after returning to work. Thus, PS's budget constraint before welfare reform $(R=0)$ is

$c_{t}(A \mid O=1, R=0)= \begin{cases}A(P-K)+(1-A) P & (t=0) \\ A P+(1-A)(P-k) & \left(0<t \leq T_{1}\right) \\ A Y+(1-A)(P-k) & \left(T_{1}<t \leq T_{0}\right) \\ Y & \left(t>T_{0}\right)\end{cases}$

If time limit $\tau$ is the maximum number of months PS can receive public assistance, and it is less than PS's planning horizon $\left(\tau<T_{1}<T_{0}\right)$, welfare reform $(R=1)$ alters the budget constraint above:

$$
c_{t}(A \mid O=1, R=1)= \begin{cases}A(P-K)+(1-A) P & (t=0) \\ A P+(1-A)(P-k) & (0<t<\tau) \\ A Y+(1-A)(Y-k) & \left(\tau \leq t \leq T_{0}\right) \\ Y & \left(t>T_{0}\right)\end{cases}
$$

In the second scenario, PS does not have other children $(O=0)$ and is working a low wage job. Because she has no other children, her planning horizon is $T_{0}$. Choosing termination means PS continues to work and earn $Y$ per month. Choosing birth, however, means childless PS stops working and enrolls in public assistance. Hence, her budget constraint pre-reform $(R=0)$ is

$$
c_{t}(A \mid O=0, R=0)= \begin{cases}A(Y-K)+(1-A) Y & (t=0) \\ A Y+(1-A)(P-k) & \left(0<t \leq T_{0}\right) \\ Y & \left(t>T_{0}\right)\end{cases}
$$

but is

$$
c_{t}(A \mid O=0, R=1)= \begin{cases}A(Y-K)+(1-A) Y & (t=0) \\ A Y+(1-A)(P-k) & (0<t \leq \tau) \\ A Y+(1-A)(Y-k) & \left(\tau<t \leq T_{0}\right) \\ Y & \left(t>T_{0}\right)\end{cases}
$$

post reform. With regard to time limit $\tau$, because childless PS is not enrolled in public assistance in period 0 , 
she can remain on assistance until month $\tau$. PS with children, on the other hand, was enrolled in public assistance in month 0 , meaning she must exit public assistance the month before $\tau$ is reached. Thus, $0<t<\tau$ is used in Equation (1.1) but $0<t \leq \tau$ is used in Equation (2.1)

\subsection{Constrained Lifetime Utility}

Given the budget constraints above, PS maximizes the same lifetime utility function that the agent in [5] maximizes:

$$
U=\sum_{t=0}^{\infty} \rho^{t} u_{t}
$$

where $\rho \in(0,1)$, and $u\left(c_{t}, A\right)=c_{t}-a \theta^{t} A-b \phi^{t}(1-A)$. Equation (3) is adapted from the model in [13] with the agent's decisions collapsing to pregnancy termination $(A=1)$ or birth $(A=0)$. Periodic utility function $u$ exhibiting constant marginal utility of consumption equaling 1 follows from [14]. If $\theta$ and $\varphi$ are both in interval $(0,1)$, then $a \theta^{t}$ and $b \phi^{t}$ are asymptotic in $t$. These expressions model pregnancy termination remorse and out-of-wedlock childbearing regret waning over time, respectively. Substituting the budget constraints into (3) gives

$$
V(A \mid O, R)=\sum_{t=0}^{\infty} \rho^{t} c_{t}(A \mid O, R)-\alpha A-\beta(1-A)
$$

where

$$
\alpha=\sum_{t=0}^{\infty} a(\rho \theta)^{t}=\frac{a}{1-\rho \theta}
$$

and

$$
\beta=\sum_{t=0}^{\infty} b(\rho \phi)^{t}=\frac{b}{1-\rho \phi}
$$

The difference in PS's lifetime utility between choosing pregnancy termination and proceeding with an outof-wedlock birth is given by

$$
\Delta V_{O, R} \equiv V(1 \mid O, R)-V(0 \mid O, R)
$$

or

$$
\Delta V_{O, R}=\beta-\alpha+\sum_{t=0}^{\infty} \rho^{t}\left[c_{t}(1 \mid O, R)-c_{t}(0 \mid O, R)\right]
$$

Equation (5) is the gain (or loss) in PS's lifetime utility resulting from choosing pregnancy termination over an out-of-wedlock birth. Its value depends on several factors like, for example, PS's disutility of pregnancy termination $(\alpha)$ relative to her disutility of out-of-wedlock $(\beta)$, the value of public assistance payment $P$ relative to what she can earn in the labor market $(Y)$, the one-time cost of pregnancy termination $(K)$, the monthly costs of raising children, the age of her youngest child $\left(T_{A}\right)$, the length of welfare reform's time limit $(\tau)$, whether she has other children or not, and whether or not welfare reform has been enacted.

\subsection{Welfare Reform's Effect on Pregnancy Termination}

In this section, the marginal benefits of pregnancy termination before and after welfare reform is enacted are compared for PS who has other children to one who does not. For childless PS, Equation (5) simplifies to

$$
\Delta V_{0,0}=\beta-\alpha-K+\frac{\rho-\rho^{T_{0}+1}}{1-\rho} k+\frac{\rho-\rho^{T_{0}+1}}{1-\rho}(Y-P)
$$

but when public assistance is limited to $\tau$ months Equation (5) simplifies to

$$
\Delta V_{0,1}=\beta-\alpha-K+\frac{\rho-\rho^{T_{0}+1}}{1-\rho} k+\frac{\rho-\rho^{\tau+1}}{1-\rho}(Y-P) .
$$

Given values of $K$ and $k$, suppose policy makers picked $P$, which happened to make childless PS indifferent between birth and termination when continued participation in public assistance was unlimited. Thus, $0=$ $\Delta V_{0,0}$, which can be expanded as follows:

$$
\begin{aligned}
0=\Delta V_{0,0}= & {\left[\beta-\alpha-K+\frac{\rho-\rho^{T_{0}+1}}{1-\rho} k+\frac{\rho-\rho^{\tau+1}}{1-\rho}(Y-P)\right] } \\
& +\frac{\rho^{\tau+1}-\rho^{T_{0}+1}}{1-\rho}(Y-P)
\end{aligned}
$$

Replacing the expression in ['] with $\Delta V_{0,1}$, and simplifying yields

$$
\Delta V_{0,1}=\frac{\rho^{\tau+1}-\rho^{T_{0}+1}}{1-\rho}(P-Y),
$$

which is positive because $P>Y$, and $0<\rho<1$ and $\tau<T_{0}$ imply $\rho^{\tau+1}>\rho^{T_{0}+1}$. Thus, imposing a time limit welfare receipt increases termination incidence among low-income childless pregnant singles, and simultaneously inhibits their enrollment in public assistance.

For PS mother, Equation (7) simplifies to

$$
\Delta V_{1,0}=\beta-\alpha-K+\frac{\rho-\rho^{T_{0}+1}}{1-\rho} k+\frac{\rho^{T_{1}+1}-\rho^{T_{0}+1}}{1-\rho}(Y-P)(8)
$$

but when public assistance is limited to $\tau$ months Equation (5) simplifies to

$$
\Delta V_{1,1}=\beta-\alpha-K+\frac{\rho-\rho^{T_{0}+1}}{1-\rho} k .
$$

Because $\Delta V_{0,0}$ can be expanded as follows

$$
\begin{aligned}
\Delta V_{0,0}= & {\left[\beta-\alpha-K+\frac{\rho-\rho^{T_{0}+1}}{1-\rho} k+\frac{\rho^{T_{1}+1}-\rho^{T_{0}+1}}{1-\rho}(Y-P)\right] } \\
& +\frac{\rho-\rho^{T_{1}+1}}{1-\rho}(Y-P)
\end{aligned}
$$


And $\Delta V_{0,0}=0$, the expression in [-] is simply $\Delta V_{1,0}$. Making the switch and simplifying yields

$$
\Delta V_{1,0}=\frac{\rho-\rho^{T_{1}+1}}{1-\rho}(P-Y)
$$

which is positive because $P>Y$, and $0<\rho<1$ and $0<T_{1}$ imply $\rho^{1}>\rho^{T_{1}+1}$. Thus, prior to the imposition of a time limit, a childless PS who is indifferent between termination and out-of-wedlock birth chooses termination if she was already the mother of other children.

Similarly, because $\Delta V_{0,0}$ can be written as

$$
\Delta V_{0,0}=\left[\beta-\alpha-K+\frac{\rho-\rho^{T_{0}+1}}{1-\rho} k\right]+\frac{\rho-\rho^{T_{0}+1}}{1-\rho}(Y-P)
$$

And $\Delta V_{0,0}=0$, the expression in [-] is simply $\Delta V_{1,1}$. Making the switch and simplifying yields

$$
\Delta V_{1,1}=\frac{\rho-\rho^{T_{0}+1}}{1-\rho}(P-Y)
$$

which is positive because $P>Y$, and $0<\rho<1$ and $0<T_{0}$ imply $\rho^{1}>\rho^{T_{0}+1}$. Because $T_{1}<T_{0}$,

$$
\text { or } \begin{gathered}
\rho-\rho^{T_{1}+1}<\rho-\rho^{T_{0}+1} \\
\quad \text { or } \Delta V_{1,0}<\Delta V_{1,1}
\end{gathered}
$$

Thus, limiting the length of time a PS can remain on public assistance makes pregnancy termination more likely for those with other children.

Interestingly enough, the model indicates that pregnancy termination is a more difficult decision for childless PS who is faced with public assistance time limits than it is for PS mothers not faced with time limits. Expanding $\Delta V_{1,0}$ as follows illustrates this

$$
\Delta V_{1,0}=\left[\frac{\rho^{\tau+1}-\rho^{T_{1}+1}}{1-\rho}(P-Y)\right]+\frac{\rho-\rho^{\tau+1}}{1-\rho}(P-Y)
$$

Because the quantity in ['] is $\Delta V_{0,1}$, rearranging the above result gives

$$
\Delta V_{0,1}=\Delta V_{1,0}-\frac{\rho-\rho^{\tau+1}}{1-\rho}(P-Y)
$$

Therefore, if low-skilled childless PS females are indifferent between pregnancy termination and out-ofwedlock birth before time limits are posed, the following holds:

$$
0=\Delta V_{0,0}<\Delta V_{0,1}<\Delta V_{1,0}<\Delta V_{1,1} .
$$

Thus, the gain to pregnancy termination is greatest for a PS female who has other children and is faced with time limits on public assistance. This is followed in declining order by a PS who has other children and is entitled to public assistance payments over her lifespan, a childless PS who is faced with time limits, and a childless PS who is entitled to continuous public assistance.

\subsection{Other Policy Effects}

Comparative static analysis is used to examine how other policies like childcare and abortion subsidies and the value of public assistance payments affect pregnancy terminations of both types of PS before and after welfare reform. Because $\Delta V_{O, R}$ can be expressed in terms of $\Delta V_{1,1}$ for all $O$ and $R$, all are rewritten as follows.

$$
\begin{gathered}
\Delta V_{0,0}=\Delta V_{1,1}-\frac{\rho-\rho^{T_{0}+1}}{1-\rho}(P-Y), \\
\Delta V_{0,1}=\Delta V_{1,1}-\frac{\rho-\rho^{\tau+1}}{1-\rho}(P-Y), \\
\Delta V_{1,0}=\Delta V_{1,1}-\frac{\rho^{T_{1}+1}-\rho^{T_{0}+1}}{1-\rho}(P-Y) .
\end{gathered}
$$

Doing the above simplifies the analysis greatly.

The devoutness or religiosity of PS affects pregnancy termination [15] via regret parameter $\alpha$. If religion is more important in period 2 than it is in period 1, PS in the more religious period will be more reluctant to choose pregnancy termination $\left(a_{2}>a_{1}\right)$. If the difference in $\alpha_{2}$ and $\alpha_{1}$ is large enough such that the gain to PS mothers faced with time limits is negative $\left(\Delta V_{1,1}<0\right)$, the gains are negative for all others:

$$
\Delta V_{0,0}<\Delta V_{0,1}<\Delta V_{1,0}<\Delta V_{1,1}<0
$$

Thus, policies that are designed to humanize the fetus reduce abortion incidence. The intuitive nature of this result lends credence to the model, and the policy implications that follow.

Policy makers wishing to reduce terminations among low-income PS mothers can affect it via changes to childcare and abortion costs:

$$
\frac{\partial \Delta V_{1,1}}{\partial k}=\frac{\rho-\rho^{T_{0}+1}}{1-\rho} \text { and } \frac{\partial \Delta V_{1,1}}{\partial K}=-1
$$

Because $\partial \Delta V_{1,1} / \partial k$ is positive due to $0<\rho<1$ and $T_{0}>0$, subsidizing childcare (reducing $k$ ) reduces the gains to abortion. The partial derivative on the left indicates that raising the cost of abortion via reducing abortion subsidies or restricting its access (physically or legally) reduces the gains associated with it [16]. If either action is such that the gain to a PS mother who is faced with time limits is negative $\left(\Delta V_{1,1}<0\right)$, property (10) holds.

Policy makers can affect reductions in pregnancy terminations by raising public assistance payment $P$ because the following partial derivatives are all negative:

$$
\frac{\partial \Delta V_{0,0}}{\partial P}=-\frac{\rho-\rho^{T_{0}+1}}{1-\rho},
$$




$$
\frac{\partial \Delta V_{0,1}}{\partial P}=-\frac{\rho-\rho^{\tau+1}}{1-\rho},
$$

and

$$
\frac{\partial \Delta V_{1,0}}{\partial P}=-\frac{\rho^{T_{1}+1}-\rho^{T_{0}+1}}{1-\rho} .
$$

If the increase in public assistance payment $P$ is large enough to make the gain to abortion for a PS mother who is faced with time limits negative $\left(\Delta V_{1,1}<0\right)$, property (10) holds. This makes sense given that raising payment $P$ reduces the cost of raising children.

\section{Conclusions}

The results in this paper indicate a behavioral response to time limits may simultaneously reduce welfare program enrollment and increase abortion incidence among lowincome childless single pregnant females. With respect to low-income pregnant single mothers, time limits trigger abortion and shorter stays on welfare. Both of these results suggest that future empirical work should account for simultaneity of abortion incidence and welfare participation.

This paper also informs policy. The results indicate that time limits, childcare and abortion subsidies, and public assistance payments are linked to abortion incidence. Welfare reform in general could be driving much of the decadal decline in the abortion rate. The results also help to support the CDC's claim that factors such as abortion access, state laws, the economy, and access to healthcare and contraception contribute to the reduction in abortion incidence.

\section{REFERENCES}

[1] CDC, "Abortion Surveillance-United States," 2009.

[2] M. Camasso, "Isolating the Family Cap Effect on Fertility Behavior: Evidence from New Jersey's Family Development Program Experiment," Contemporary Economic Policy, Vol. 22, No. 4, 2004, pp. 453-467. doi:10.1093/cep/byh034

[3] T. Joyce, R. Kaestner, S. Korenman and S. Henshaw, "Family Cap Provisions and Changes in Births and Abortions," Population Research and Policy Review, Vol. 23, No. 5-6, 2004, pp. 475-511. doi:10.1007/s11113-004-3461-7

[4] J. Klerman, "Fertility Effects of Medicaid Funding of Abortions: A Disaggregated Analysis," Mimeo, RAND, Santa Monica, 1998.

[5] H. Snarr and J. Edward, "Does Income Support Increase Abortions?" Social Choice and Welfare, Vol. 33, No. 4, 2009, pp. 575-599. doi:10.1007/s00355-009-0380-x

[6] Social Security Act-Sec. 401. [42 U.S.C. 601] (a)(2)

[7] Social Security Act-Sec. 401. [42 U.S.C. 601] (a)(3)

[8] 2001 TANF Annual Report to Congress. www.acf.hhs.gov/programs/ofa/data-reports/ar2001/chapt er08.pdf

[9] G. Rowe and J. Versteeg, "Welfare Rules Databook: State TANF Policies as of July 2003," Urban Institute, 2005. www.urban.org/UploadedPDF/411183_WRD_2006.pdf

[10] C. Harvey and M. Berkowitz, "Review of Diversion Programs," Disability Research Institute, 2006. www.dri.uiuc.edu/research

[11] H. Snarr, "Was It the Economy or Reform That Precipitated the Steep Decline in the Welfare Caseload?" Applied Economics, Vol. 45, No. 4, 2013, pp. 525-540. doi:10.1080/00036846.2011.607135

[12] L. Stevans, "Aid to Families with Dependent Children (AFDC) and Non-Marital Births in the USA: An Examination of Causality," Applied Economics, Vol. 28, No. 4, 1996, pp. 417-427. doi:10.1080/000368496328542

[13] T. Kane and D. Staiger, "Abortion Access and Teen Motherhood," The Quarterly Journal of Economics, Vol. 111, No. 2, 1996, pp. 467-506. doi:10.2307/2946685

[14] H. Fang and D. Silverman, "On the Compassion of TimeLimited Welfare Programs," Journal of Public Economics, Vol. 88, No. 7-8, 2004, pp. 1445-1470. doi:10.1016/S0047-2727(02)00183-4

[15] R. King, S. Myers and D. Byrne, "The Demand for Abortion by Unmarried Teenagers: Economic Factors, Age, Ethnicity and Religiosity Matter," American Journal of Economics and Sociology, Vol. 51, No. 2, 1992, pp. 223235. doi:10.1111/j.1536-7150.1992.tb03349.x

[16] M. Medoff, "The Determinants and Impact of State Abortion Restrictions," American Journal of Economics and Sociology, Vol. 61, No. 2, 2002, pp. 481-493. doi:10.1111/1536-7150.00169 